\title{
Self-Care of Adolescents with Type 1 Diabetes Mellitus: Knowledge about the Disease
}

\author{
Autocuidado dos Adolescentes com Diabetes Mellitus Tipo 1: Conhecimento acerca da Doença \\ Autocuidado de los Adolescentes con Diabetes Mellitus Tipo 1: Conocimiento sobre la \\ Enfermedad
}

Marília Costa Flora*; Manuel Gonçalves Henriques Gameiro**

\begin{abstract}
Background: Type 1 Diabetes Mellitus (T1DM) is an increasingly prevalent disease in adolescence. Self-management of diabetes is highly important for adolescents to gain autonomy and to reduce associated risks.

Objectives: To identify the knowledge of adolescents with T1DM about the disease and respective care; to analyze the relationship between the knowledge of adolescents with T1DM about the disease and respective care and age and gender.

Methodology: Descriptive-analytical and cross-sectional study. The sample was composed of a total of 51 adolescents aged between 12 and 18 years being followed-up in diabetes consultations in the center region of Portugal. A knowledge test was applied.

Results: Although most adolescents had a good level of overall knowledge about diabetes and in 3 of the 5 dimensions, the study revealed some misconceptions, as well as adolescents with a low level of knowledge. Positive correlations were found between the adolescents' knowledge and age.

Conclusion: It is important to correct misconceptions and identify the adolescents with insufficient knowledge so as to provide a more targeted intervention.
\end{abstract}

Keywords: adolescent; type 1 diabetes mellitus; self-care; autonomy; nursing

\section{Resumo}

Enquadramento: A diabetes mellitus tipo 1 (DM 1) é uma doença cada vez mais prevalente na adolescência. O controlo da doença no âmbito do autocuidado revela-se de grande valor na conquista da autonomia dos adolescentes e na diminuição dos riscos associados.

Objectivos: Analisar o conhecimento dos adolescentes diabéticos acerca da doença e dos cuidados; verificar a relação do conhecimento dos adolescentes com DM1 acerca da doença e dos cuidados com a idade e o sexo.

Metodologia: Estudo descritivo-analítico e transversal. Participaram 51 adolescentes com idades entre os 12 e os 18 anos, seguidos em consultas de diabetologia de hospitais da zona centro de Portugal, tendo-se aplicado um teste de conhecimentos.

Resultados: Relativamente ao conhecimento, no global e em 3 das 5 dimensões, a maioria dos adolescentes demonstrou conhecimento de nível bom, todavia foram identificados conceitos erróneos tendo-se registado adolescentes com baixo nível de conhecimentos. Verificam-se correlações positivas do conhecimento com a idade dos adolescentes.

Conclusão: É importante corrigir os conceitos erróneos e identificar os adolescentes com conhecimento insuficiente, para uma intervenção dirigida.

Palavras-chave: adolescente; diabetes mellitus tipo 1; autocuidado; autonomia; enfermagem

\footnotetext{
* MSc., RN, Specialist in Child Health and Pediatric Nursing, Nursing School of Coimbra, 3046-851 Coimbra, Portugal [liaflora@esenfc.pt]. Contribution to the article: literature search, data collection with application of questionnaire, data treatment, analysis and discussion, article writing. Addres for correspondence: Rua 1. ${ }^{\circ}$ de Maio, Lote $58 \mathrm{~B}, 2^{\circ}$ Dir, Edifício Gardénia, Chã, 3046-851, Portugal. * MSc., Coordinating Professor, Nursing School of Coimbra, 3046-851 Coimbra, Portugal [mgameiro@esenfc.pt].Contribution to the article: supervision of the master's thesis. Collaboration in data treatment, analysis and discussion, supervision in article writing.
}

\section{Resumen}

Marco contextual: La diabetes mellitus tipo 1 es una enfermedad cada vez más común en la adolescencia. El control de la enfermedad en el ámbito del autocuidado es muy importante para conseguir la autonomía de los adolescentes y la disminución de los riesgos asociados.

Objetivos: Analizar lo que los adolescentes con diabetes saben sobre la enfermedad y los cuidados; comprobar la relación entre lo que los adolescentes con DM1 saben sobre la enfermedad y los cuidados, y la edad y el sexo.

Metodología: Estudio descriptivo-analítico y transversal en el que participaron 51 adolescentes con edades entre los 12 y los 18 años a los que se les hizo un seguimiento en consultas de diabetología de hospitales de la zona centro de Portugal, así como una prueba de conocimientos.

Resultados: En relación al conocimiento, en general y en 3 de las 5 dimensiones, la mayoría de los adolescentes demostró tener un conocimiento bueno, aunque se identificaron algunos conceptos erróneos y se registró a adolescentes con un bajo nivel de conocimiento. Se verificaron correlaciones positivas entre el conocimiento y la edad de los adolescentes. Conclusión: Es importante corregir los conceptos erróneos e identificar a los adolescentes con un conocimiento insuficiente para intervenir de forma dirigida.

Palabras clave: adolescente; diabetes mellitus tipo 1; autocuidado; autonomía; enfermería

Received for publication: 07.05 .15

Accepted for publication: 04.02.16 


\section{Introduction}

Type 1 diabetes mellitus (T1DM) "is an autoimmune disease characterized by the progressive destruction of pancreatic beta cells which will result in the interruption of insulin production and, consequently, severe metabolic imbalance" (Miculis, Mascarenhas, Boguszewski, \& Campos, 2010, p. 276).

In Portugal, the number of new cases of diabetes diagnosis increases every year. According to the National Observatory of Diabetes, the incidence of diabetes in 2014 was 17.5\% (261 new cases) for each 100,000 inhabitants aged 0-14 years, whereas in 2000, the incidence was $9.5 \%$ (160 new cases; Sociedade Portuguesa de Diabetologia, 2015). These results are in line with the international trend of increase of T1DM at increasingly younger ages.

T1DM is associated with several complications, particularly increased mortality and high risk of micro and macrovascular complications. Diabetes is a predisposing factor for retinopathy, neuropathy and nephropathy, cardiovascular diseases and diabetic foot (Santos, Silva, \& Cardoso, 2009). As a chronic disease, it is also responsible for a significant health burden, as well as for reduced work capacity and lower life expectancy (Góes, Vieira, \& Júnior, 2007). Well-controlled diabetes reduces the associated complications and underlying social and economic costs, namely those related to health care, loss of income, social expenditure, loss of productivity, and also costs associated with missed opportunities for economic development (Sociedade Portuguesa de Diabetologia, 2015).

In this study, we focus on the concept of adolescence as defined by the World Health Organization, which adopts the chronological criterion that covers young people aged between 10 and 19 years (World Health Organization, 2011). Due to its very specific developmental characteristics, adolescence is a period of major changes that require from the adolescents and their families a significant effort of adapt to chronic illness, as well as a differentiated intervention by the health care teams. Diabetes demands a reorganization of the personal and family routines at several levels, implying not a cure, but rather a daily management (Ribeiro, 1998). Therefore, we believe that there is an urgent need for a more interventive action among adolescents, which represents a challenge for health care services and in particular for nurses. An early and sustained intervention by the health care teams will impact the well-being and quality of life of diabetic adolescents and their families by reducing their anxiety and debilitated emotional status (Aguiar \& Fonte, 2007). An optimized treatment of T1DM since the diagnosis stage allows patients to achieve a good metabolic control, preventing complications and ensuring a smooth integration into the social, academic and professional lives. As first-rate professionals, nurses, in particular the nurse specialist in child health and pediatrics, can develop a privileged work among adolescents with T1DM and take into account the families' potential vulnerabilities.

Based on this problematic background, a descriptive and analytic study was conducted with a population of adolescents with T1DM, with the following objectives: to identify the knowledge of adolescents with T1DM about the disease and respective care; and to analyze the relationship between the knowledge of adolescents with T1DM about the disease and respective care and age and gender.

\section{Background}

T1DM is an increasingly prevalent chronic disease in adolescence, whose diagnosis and treatment results, in most cases, in a strong emotional impact on patients, particularly adolescents (Aguiar \& Fonte, 2007). As regards the impact of diabetes on adolescents and their families, this disease can affect the behavioral, somatic, social and financial areas. This is a phase where adolescents become more independent from their parents' responsibility and start to define their self with the consolidation of the sense of belonging to groups of peers. Here, they try to define their personal identity, deepen their relationships with peers, intensify intellectual interests, and develop a sense of social belonging (Sampaio, 2010).

In addition, the knowledge of diabetic adolescents about the disease is determinant to the adoption of behaviors. According to Karlsson, Arman, and Wikblad (2008), the lack of knowledge about the physical processes related to diabetes promotes insecurity in adolescents concerning the treatment based on the triad of diet, physical exercise and insulin therapy, and also concerning their accountability and autonomy. Knowledge is conditioned by the social and cultural beliefs of the environment where adolescents are 
inserted, negatively or positively influencing disease management. According to the self-regulation model of illness representation, individuals create mental representations, namely disease-related beliefs which condition the behaviors and, consequently, the outcomes (Leventhal et al., 1980, cited by Nouwen, Urquhart Law, Hussain, McGovern, \& Napier, 2009). As for self-care, "it is a regulatory human function that individuals deliberately perform for themselves or have performed for them to maintain life, health, development and well-being" (Tomey \& Alligood, 2002, cited by Queirós, Vidinha, \& Filho, 2014). Thus, self-care is based on the activities that individuals perform in an effective and responsible way to maintain life, health and well-being (Ataíde \& Damasceno, 2010).

The provision of nursing care sustained by the Self-Care Theory has proved to be an effective alternative to encourage patients to actively participate in their treatment, increasing their accountability for the outcomes (Peixoto, 1996). Nursing is particularly concerned with the need for the individual to perform self-care activities on a permanent basis to sustain life and health, recover from disease or cope with its effects (Orem, 1991). With regard to diabetes self-care, adolescents with T1DM are encouraged to periodically attend consultations for urine and blood testing, insulin administration, adjustment of insulin in relation to the consumption of carbohydrates and physical exercise (Rosalind, 2006). Thus, self-care includes: insulin administration, blood glucose monitoring, maintaining records of insulin administration and glucose levels, management of hypoglycemia and hyperglycemia, complying with meal plans and exercising regularly (Chien, Larson, Nakamura, \& Lin, 2007). In view of the above, it is relevant to understand how each adolescent interprets, apprehends and builds the illness process in terms of the therapeutic demands, but also the adaptation to the social context.

\section{Research questions}

How is the knowledge of adolescents with T1DM characterized in general terms and in the relevant dimensions of self-care?

Is there an association between this knowledge and the adolescents' age and gender?

\section{Methodology}

Before the application of the questionnaire, we requested written authorizations from the board of directors of the District Hospital of Figueira Da Foz, EPE (HDFF, EPE), the board of directors of the Baixo Vouga Hospital Center, EPE (CHBV, EPE), and an association for patients with diabetes (AD). The study began after the favorable opinion from the ethics committees of these institutions. This is a quantitative, descriptive-analytical and cross-sectional study. According to the model of analysis proposed, our key variable was the knowledge about T1DM and associated care. As regards the other variables, we considered the adolescents' demographic characteristics of age and gender.

\section{Population and Sample}

Of the total sample, 32 adolescents (62.7\%) were recruited in the endocrinology consultation of $\mathrm{CHBV}$, EPE; 11 adolescents (21.6\%) being followed-up in hospitals of the central region were recruited during the field activities of an $\mathrm{AD}$; and eight adolescents (15.7\%) in the endocrinology consultation of HDFF, EPE. An accidental sampling method was used, since the adolescents were being integrated into the study as they attended the consultations/AD meetings and only when the researcher was present. Data were collected between September 2012 and February 2013.

In relation to gender, the sample is balanced as 25 adolescents (49\%) were girls and 26 adolescents (51\%) were boys. As regards age, the mean age of the group was 15 years $(S D=2.07 ; M d=15)$. The selected age groups, of similar size, show a homogenous distribution. However, there is a higher prevalence of adolescents aged between 12-14 years. The 12-14 age group is composed of 21 adolescents (41.2\%), followed by the 15-17 age group with 19 adolescents (37.3\%), and the $>17$ age group with 11 adolescents (21.6\%). All the respondents lived in the central region of Portugal.

\section{Instrument}

We designed a knowledge test about T1DM and associated care (Table 1). This is a multiple choice test in which one answer is correct out of three alternative answers. It is subdivided into five areas of knowledge about the disease: nature/pathophysiology of the 
disease (25\%), acute and chronic complications of T1DM (30\%), insulin administration (15\%),

Table 1

Domains of knowledge included in the test

\begin{tabular}{ll}
\hline \multirow{2}{*}{ Nature/pathophysiology of the disease (25\%) } & $\begin{array}{l}\text { Concept of DM1 } \\
\text { Causes for DM1 } \\
\text { Organ that produces insulin } \\
\text { Symptoms of hyperglycemia } \\
\text { Causes for variations in blood sugar levels }\end{array}$ \\
\hline & $\begin{array}{l}\text { Concept of hypoglycemia } \\
\text { Causes for hypoglycemia } \\
\text { Acute and chronic complications of the disease (30\%) }\end{array}$ \\
& $\begin{array}{l}\text { Symptoms of hypoglycemia } \\
\text { Procedures in case of hypoglycemia } \\
\text { Concept of hyperglycemia }\end{array}$ \\
& Complications of poorly managed diabetes \\
\hline \multirow{2}{*}{ Insulin administration (15\%) } & $\begin{array}{l}\text { Sites for insulin administration } \\
\text { Storage and conservation of insulin } \\
\text { Measures to be taken while administrating insulin with an insulin pen }\end{array}$ \\
\hline \multirow{2}{*}{ Mealth maintenance (20\%) } & How to measure capillary blood glucose \\
& How to change the lancet to measure capillary blood glucose \\
\hline
\end{tabular}

In addition to the level of knowledge about the disease, we calculated the percentage of answers to the various alternatives in order to identify any misconceptions. Misconceptions are interpreted as answers that, despite being wrong, were considered as being correct by more than $25 \%$ of the adolescents. The content validity of the instrument was assessed by experts in the area of diabetology, in particular a pediatrician, a diabetology nurse, and an endocrinologist, and adjustments were made according to their suggestions. We also analyzed the dispersion of the answers, by calculating the means between 0 and 1 and the standard deviation of the answers to each item. We found that all questions discriminated with very measurement of capillary blood glucose (10\%), and health maintenance (20\%). 


\section{Data Collection}

The specific days for application of the instrument were previously scheduled with the nursing teams of the institutions and with the person responsible for the $\mathrm{AD}$. Before applying the instrument, the adolescents and legal guardians were explained the nature of the study, its objective and purpose, as well as ensured of the data anonymity. The instrument was applied after the adolescents and the legal guardians signed the informed consent. The questionnaires were answered on an individual basis during approximately 15 minutes.

\section{Results}

In relation to the knowledge of adolescents with T1DM about the disease and associated care, we analyzed the overall knowledge and the knowledge per domain, and identified the misconceptions existing in the population of diabetic adolescents.

\section{Level of Knowledge of Diabetic Adolescents about the Disease and Care:}

In relation to the knowledge about the disease by domain of knowledge, an analysis of knowledge was performed in the five domains (Table 3), with a variation from $0 \%$ to $100 \%$, and the median for each domain ranged between $66.7 \%$ and $100 \%$. As regards the average knowledge in each domain, it ranged from $73.9 \%$ to $88.2 \%$. In general, the level of knowledge of this population varied between reasonable and good. As regards the overall knowledge about diabetes and associated care, $50.9 \%(M d=85)$ of the adolescents has a good level of knowledge. Most adolescents showed a good level of knowledge in the following dimensions: acute and chronic complications of the disease (76.4\%) and nature/pathophysiology of the disease (60.8\%). On the other hand, few adolescents showed a good level of knowledge in the following dimensions: health maintenance (29.4\%) and insulin administration (39.2\%). The measures of central tendency point in the same direction, with higher mean and median scores found in the dimensions related to the chronic and acute complications of the disease and the nature/pathophysiology of the disease. The greatest variation was found in the domain related to the measurement of capillary blood glucose. A worrying aspect is the percentage of adolescents with insufficient knowledge, where $17.6 \%$ and $13.7 \%$ of adolescents show a low level of knowledge regarding insulin administration and chronic and acute complications of the disease, respectively.

Table 3

Levels of knowledge about the disease by domain of knowledge and overall knowledge

\begin{tabular}{lccccccccc}
\hline \multirow{2}{*}{ Domain of knowledge about the disease } & \multicolumn{3}{c}{$<50 \%$} & \multicolumn{2}{c}{$50-80 \%$} & \multicolumn{3}{c}{$80-100 \%$} & \multicolumn{3}{c}{$0 \%$ a $100 \%$} \\
\cline { 2 - 10 } & $n$ & $\%$ & $n$ & $\%$ & $n$ & $\%$ & $M d$ & $\overline{\mathrm{X}}$ & $S D$ \\
\hline Nature/pathophysiology of the disease & -- & 0.0 & 20 & 39.2 & 31 & 60.8 & 100.0 & 88.2 & 16.0 \\
Acute and chronic complications of the disease & 7 & 13.7 & 5 & 9.8 & 39 & 76.4 & 83.3 & 83.3 & 19.0 \\
Insulin administration & 9 & 17.6 & 22 & 43.1 & 20 & 39.2 & 66.7 & 73.9 & 24.0 \\
Assessment of capillary blood glucose & 1 & 2.0 & 23 & 45.1 & 27 & 52.9 & 100.0 & 75.5 & 27.0 \\
Health maintenance & 4 & 7.9 & 32 & 62.8 & 15 & 29.4 & 75.0 & 74.0 & 23.0 \\
Overall knowledge & 3 & 5.9 & 22 & 43.0 & 26 & 50.9 & 85.0 & 80.5 & 13.0 \\
\hline
\end{tabular}

\section{Misconceptions}

Another relevant aspect concerning the knowledge about diabetes is the identification of misconceptions. To this end, we analyzed the adolescents' answers to each question (Table 4).

With regard to the observed misconceptions regarding the procedures in case of a symptomatic hypoglycemia, $25.5 \%$ of the adolescents believe that they must take a sugar packet and reassess blood glucose within 10 to 15 minutes, undervaluing the subsequent ingestion of slowly absorbed carbohydrates. These adolescents do not recognize the ingestion of slowly absorbed carbohydrates as a way to maintain their blood glucose levels. When asked about the practice of physical exercise, $39.2 \%$ of the adolescents mention that it is important to measure blood glucose and ingest rapidly absorbed carbohydrates. These adolescents undervalue the correct alternative related to the management of insulin before the practice of physical exercise. In relation to insulin storage, 
most adolescents (51\%) believe that, after opening the cartridge, it must be kept in the fridge. There is clearly an underlying misconception here regarding the insulin preservation in the cartridge in use. When asked about the replacement of the lancet, 27.5\% of the adolescents referred that it must be replaced after each puncture. Here, adolescents reveal a poor management of the consumables.

Table 4

Conhecimento acerca da doença: distribuição das respostas por item $(n=51)$
Therefore, across the various domains of knowledge, the diabetic adolescents revealed that some of their self-care practices were based on misconceptions. We can infer that there is a significant percentage of adolescents with misconceptions about T1DM and respective care, with the exception of the domain related to the nature/pathophysiology of the disease.

\begin{tabular}{|c|c|c|c|c|c|c|}
\hline \multirow[t]{2}{*}{ Answers } & \multicolumn{2}{|c|}{ A } & \multicolumn{2}{|c|}{ B } & \multicolumn{2}{|c|}{$\mathrm{C}$} \\
\hline & no. & $\%$ & $n o$. & $\%$ & no. & $\%$ \\
\hline \multicolumn{7}{|l|}{ Nature/pathophysiology of the disease } \\
\hline 1.What is T1DM? & 46 & 90.2 & 4 & 7.8 & 1 & 2.0 \\
\hline 2.What are the causes for T1DM? & 8 & 15.7 & -- & 0.0 & 43 & 84.3 \\
\hline 3.What is the organ than produces insulin? & 51 & 100.0 & -- & 0.0 & -- & 0.0 \\
\hline 4.What are the symptoms of a high level of sugar in the blood (hyperglycemia)? & 43 & 84.3 & 8 & 15.7 & -- & 0.0 \\
\hline 5.The variation of blood glucose is related to: & 42 & 82.4 & 8 & 15.7 & -- & 0.0 \\
\hline \multicolumn{7}{|l|}{ Acute and chronic complications of the disease } \\
\hline 6.What is hypoglycemia? & 10 & 19.6 & 40 & 78.4 & 1 & 2.0 \\
\hline 7.One of the causes for hypoglycemia is: & 6 & 11.8 & 2 & 3.9 & 43 & 84.3 \\
\hline 8.The symptoms of hypoglycemia can be: & 44 & 86.3 & 4 & 7.8 & 3 & 5.9 \\
\hline 9. What to do in case of symptomatic hypoglycemia (blood glucose $<70 \mathrm{mg} / \mathrm{dl}$ ): & 37 & 72.5 & 13 & 25.5 & 1 & 2.0 \\
\hline 10.You are hyperglycemic if: & 2 & 3.9 & 3 & 5.9 & 46 & 90.2 \\
\hline 11.What are the complications of poorly controlled diabetes? & 45 & 88.2 & 3 & 5.9 & 3 & 5.9 \\
\hline \multicolumn{7}{|l|}{ Insulin administration } \\
\hline 12.Sites for insulin administration: & 49 & 96.1 & 1 & 2.0 & 1 & 2.0 \\
\hline 13.How should insulin be stored and preserved after opening the cartridge? & 1 & 2.0 & 26 & 51.0 & 24 & 47.1 \\
\hline 14.Measures to be taken while administrating insulin using an insulin pen: & 40 & 78.4 & 1 & 2.0 & 9 & 17.6 \\
\hline \multicolumn{7}{|l|}{ Measurement of capillary blood glucose } \\
\hline 15.In the measurement of capillary blood glucose, you should: & 1 & 2.0 & -- & 0.0 & 50 & 98.0 \\
\hline $\begin{array}{l}\text { 16.The lancet used to measure capillary blood glucose should be replaced: } \\
\text { Health maintenance }\end{array}$ & \multicolumn{5}{|c|}{ Health maintenance } & 17.6 \\
\hline 17.How many meals should a diabetic adolescent have per day? & 4 & 7.8 & 44 & 86.3 & 3 & 5.9 \\
\hline 18.Can a diabetic adolescent practice physical exercise? & -- & 0.0 & 6 & 11.8 & 45 & 88.2 \\
\hline 19.Before practicing physical exercise, the adolescent should: & 24 & 47.1 & 20 & 39.2 & 7 & 13.7 \\
\hline 20.The diet of a diabetic adolescent should include: & 38 & 74.5 & 9 & 17.6 & 4 & 7.8 \\
\hline
\end{tabular}

\section{$\square$ Correct answer}

Bold: Misconceptions

\section{Relationship between Knowledge and Age} An additional statistical analysis was performed in order to investigate the existence of a relationship between the knowledge about the disease and age (Table 5).
A positive relationship was found between age and knowledge about the disease. This trend of knowledge increasing with age is particularly significant concerning the awareness of complications $(p<0.001)$ and the nature of the disease $(p<0.05)$. 
Table 5

Knowledge about the disease and age

\begin{tabular}{lcc}
\hline \multirow{2}{*}{ Knowledge about the disease } & \multicolumn{2}{c}{ Age } \\
\cline { 2 - 3 } & $r_{s}$ & $p$ \\
\hline Nature/pathophysiology of the disease & $0.304^{*}$ & 0.030 \\
Acute and chronic complications of the disease & $0.580^{* *}$ & 0.000 \\
Insulin administration & 0.090 & 0.531 \\
Assessment of capillary blood glucose & 0.020 & 0.891 \\
Health maintenance & 0.103 & 0.473 \\
Overall knowledge & $0.405^{* *}$ & 0.003 \\
\hline
\end{tabular}

Spearman's correlation; *Significant at $\mathrm{p}<0.005 ;$ **Highly significant at $\mathrm{p}<0.01$

Relationship between Knowledge and Gender

Another statistical analysis was performed in order to investigate the existence of a relationship between the knowledge about the disease and gender. To this

Table 6

Knowledge about the disease and gender end, we applied Mann-Whitney U tests (Table 6), with no significant differences being found in any of the dimensions or in the overall knowledge $(p>0.05)$.

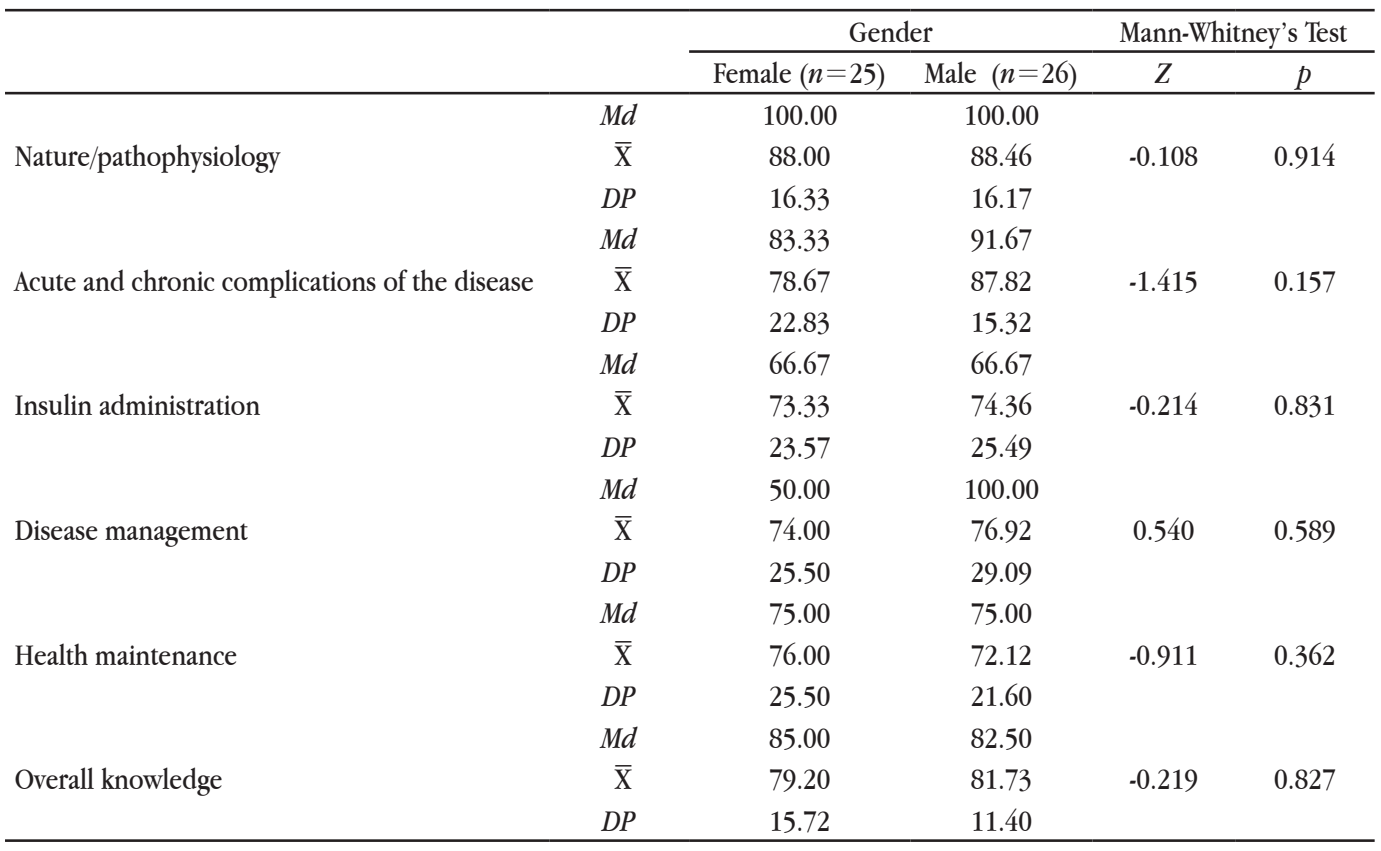

\section{Discussion}

The instrument was designed to operationalize the variable related to the knowledge about the disease. Most adolescents showed a good overall knowledge. As for the domains of knowledge, we observed that most adolescents have a reasonable to good level of knowledge between $50 \%$ and $100 \%$. However, with the exception of the domain of nature/pathophysiology of the disease, we observed that adolescents had a low level of knowledge in all the domains $(<50 \%)$. The largest percentage of adolescents with an insufficient level of knowledge was found in the domain related to insulin administration (17.6\%), followed by the domain of acute and chronic complications of the disease (13.7\%). According to Karlson et al. (2008), the lack of knowledge about diabetes-related physical processes promotes insecurity in adolescents 
regarding their ability and responsibility to manage their diet and their disease. In turn, Garcia, Brown, Kouzekanami, \& Hanis (2001) argue that, although the diabetic patient's in-depth knowledge is not a guarantee of significant behavioral changes and good self-care conduct, it is undeniable that knowledge is essential for diabetes management.

In addition to the adolescents' level of knowledge about the disease, we aimed at analyzing the misconceptions in order to understand if self-care in diabetes is conditioned by false concepts, with some of them already being discontinued practices. As regards the procedures in case of a symptomatic hypoglycemia, $25.5 \%$ of the adolescents believe that they must ingest a sugar packet and reassess blood glucose within 10 to 15 minutes, undervaluing the subsequent ingestion of slowly absorbed carbohydrates. Hypoglycemia is commonly associated with the ingestion of sucrose. The intake of slowly absorbed carbohydrates to maintain the levels of blood glucose was less often mentioned in the answers, which denotes that this is a deeply rooted concept in the target population. The same is true when asked about the practice of physical exercise: $39.2 \%$ of the adolescents mentioned that they must measure blood glucose and ingest rapidly absorbed carbohydrates. In this question, the adolescents undervalued the correct alternative of measuring insulin before the practice of physical activity. In addition to the difficulty in managing physical exercise and insulin administration, these results suggest the belief about diabetes-related limitations to the practice of physical exercise. The adolescents' main concern regarding the practice of exercise is the occurrence of hypoglycemia during or up to several hours after the physical activity, which can be discouraging. The diabetic patient has no physiological way of inhibiting insulin release, thus, insulin sensitivity is not affected by physical exercise. However, hypoglycemia can be controlled. It is important to define the type, intensity and duration of the physical activity and, consequently, reduce in $10 \%$ to $20 \%$ the insulin dose of the previous meal. Capillary blood glucose should be monitored before, during and after the physical activity, and adolescents should be provided with carbohydrates (Miculis et al., 2010). In relation to insulin storage, most adolescents (51\%) consider that, after opening the cartridge, insulin must be kept in the fridge. There is a noticeable lack of knowledge here concerning insulin storage, because nowadays it is not necessary to store insulin in the fridge after opening the cartridge. When asked about the replacement of the lancet, $27.5 \%$ of the adolescents mentioned that it must be replaced after each puncture. Here, the adolescents reveal a poor management of the consumables. It should be noted that $15.7 \%$ of the adolescents believe that their disease is a result of bad eating habits, which can be a significant factor in how the adolescent integrates and manages the disease. We can infer that some of the adolescents' knowledge about the disease is permeated by misconceptions that may condition disease management, with the exception of the domain related to the nature of the disease. Empirical studies have shown that the misconceptions about diabetes are associated with self-care, diet and emotional well-being. Skinner and Hampson (cited by Nouwen et al., 2009) argue that beliefs have a positive influence in diet management in diabetes. The belief about treatment effectiveness is a significant factor for the adherence of adolescents with T1DM to the dietary regimens (Griva, Myers, \& Newman, 2000 as cited by Nouwen et al., 2009). Iannotti et al. (2006) have associated the effectiveness of the interventions and the beliefs of diabetic adolescents about self-care and metabolic control, and the results showed that the greater the belief in the treatment, the more effective were the self-care behaviors and the metabolic control of the disease. These concepts can be influenced by variables such as the sociodemographic, cultural and economic characteristics of the environment surrounding the adolescents. These are deep-rooted habits/beliefs taken as certain that diverge from the training received in hospital settings and that influence disease management. However, nurses are first-rate professionals and play a relevant role in the education of diabetic adolescents and their families. These results, particularly concerning misconceptions, may be related to the information provided by nurses. There is a clear need for differentiated teams composed of nurses with specialized training in the area of diabetes and with specific skills to establish an effective therapeutic relationship with adolescents and their families.

An additional analysis was also performed to observe if the gender and age variables are associated with the knowledge about the disease. In relation to gender, this association was not confirmed, whereas age seems to be directly associated with the adolescents' 
knowledge about the disease, which may be justified by the level of intellectual and cognitive development and maturity. These results contradict other studies that mention that older adolescents do not believe in the efficacy of the treatment and, as such, do not comply with the treatment (Anderson, Auslander, Jung, Miller, \& Santiago, cited by Nouwen et al., 2009). The study of Nouwen et al. (2009), with a sample of 150 adolescents aged 12-18 years, also contradicts these results since older adolescents attach less importance to treatment by showing a good metabolic control.

The study revealed some limitations that conditioned the results obtained. We highlight the waiting time for the institutions to authorize the study. Regarding the number of participants, the sample size was considerably limited by the fact that most consultations took place every three months.

\section{Conclusion}

This study allowed us to identify how diabetic adolescents manage their self-care roles in what concerns their knowledge about the disease. The results have implications for nursing practice, namely in terms of monitoring diabetic adolescents and their families. Based on the results, we can state that adolescents with T1DM have a good level of knowledge about the disease; however, prevalent misconceptions were observed that may condition the disease self-care management, thus increasing the risk of long-term complications. These data may put into question the strategies and methods used when dealing with diabetic adolescents. The creation of support groups with specific moments for the adolescents to share their experiences outside the hospital could be a strategy used in a future approach. In terms of the level of knowledge, it is important to work toward correcting prevalent misconceptions, including those related to hypoglycemia, insulin storage, replacement of lancets, practice of physical exercise, and insulin administration. The misconceptions of the sample lead us to think about the nurses' role as professionals with a responsibility to educate these adolescents and their families. The identification of cases with a low level of knowledge was very important: The largest percentage was found in the domain related to insulin administration (17.6\%), followed by the domain of acute and chronic complications of the disease (13.7\%). These domains require a more targeted nursing intervention.

As regards the implications for the care practice, we believe that the inclusion of nurses specialist in child and youth health in the diabetology team, empowered with differentiated skills to promote the adjustment of the adolescents to the process of chronic disease, would be an important strategy for the success of the education of diabetic adolescents and their families.

We suggest the replication of studies in this area with the application of this instrument in other institutional contexts.

\section{References}

Aguiar, S., \& Fonte, C. (2007). Narrativas e significados da doença em crianças com diabetes mellitus tipo1. Revista Psicologia Saúde e Doenças, 8(1), 67-81. Retrieved from http://www. scielo.mec.pt/pdf/psd/v8n1/v8n1a05.pdf

Ataíde, M. B., \& Damasceno, M. M. (2010). Fatores que interferem na adesão ao autocuidado em diabetes. Revista Enfermagem UERJ, 14(4), 518-523. Retrieved from http://www.facenf.uerj. br/v14n4/v14n4a05.pdf

Chien, S. C., Larson, E., Nakamura, N., \& Lin, S. J. (2007). Self-care problems of adolescents with type 1 diabetes in Southern Taiwan. Journal Of Pediatric Nursing, 22(5), 404-409. doi:10.1016/j.pedn.2006.05.011

Garcia, A. V., Brown, S., Kouzekanami, K., \& Hanis, C. (2001). The star country diabetes education study: Development of the spanish-language diabetes knowledge questionnaire. Diabetes Care, 24(5), 16-21. doi: 10.2337/diacare.24.1.16

Góes, A. P., Vieira, M. R., \& Júnior, R. R. L.(2007). Diabetes mellitus tipo 1 no contexto familiar e social. Revista Paulista de Pediatria, 25(2), 124-128. Retrieved from http://www. redalyc.org/articulo.oa?id $=406038921005$

Iannotti, R. J., Schneider, S., Nansel, T., Heynie, D., Plotnick, l., Sobel, D., \& Morton, B. (2006). Self-efficacy, outcome expectations, and diabetes self-management in adolescents with type 1 diabetes.Journal of Developmental and Behavioral Pediatrics, 27(2), 98-105. doi: 10.1097/00004703200604000-00003

Karlsson, A., Arman, M., \& Wikblad, K. (2008). Teenagers with type 1 diabetes: A phenomenological study of the transition towards autonomy in self-management. International Journal of Nursing Studies, 45(4), 562-570. doi:10.1016/j. ijnurstu.2006.08.022

Nouwen, A., Urquhart, L. H., McGovern, S., \& Napier, H. (2009). Comparison of the role of self-efficacy and illness representations in relation to dietary self-care and diabetes distress in adolescents with type 1 diabetes. Psychologie and Health, 24(9), 1071-1084. doi: 10.1080/08870440802254597 
Miculis, C. P., Mascarenhas, L. P., Boguszewski, M. C., \& Campos, W. (2010). Atividade física na criança com diabetes tipo 1. Jornal de Pediatria, 86(4), 271-278. doi: 0021-7557/10/86-04/271

Orem, D. (1991). Nursing: Concepts of practice ( $4^{\mathrm{a}} \mathrm{ed}$.). Saint Louis, USA: Mosby.

Peixoto, M. R. (1996). Divergências e convergências entre um modelo de assistência de enfermagem a pacientes diabéticos e a teoria do déficit de autocuidado de Orem. Revista de Escola de Enfermagem São Paulo, 30(1), 1-13. Retrieved from http://www.scielo.br/pdf/reeusp/v30n1/v30n1a01.pdf

Queirós, P. J.,Vidinha, T. S., \& Filho, A. J. (2014). Autocuidado: O contributo teórico de Orem para a disciplina e profissão de enfermagem. Revista de Enfermagem Referência, 4(3), 157-164. Retrieved from http://www.scielo.mec.pt/pdf/ref/ vserIVn3/serIVn3a18.pdf

Ribeiro, J. (1998). Psicologia e Saúde. Lisboa, Portugal: ISPA.
Rosalind, B. (2006). A criança com disfunção endócrina. In M. J. Hockenberry \& Wilkenstein (Eds.), Wong fundamentos de enfermagem pediátrica (pp.1063-1095). Rio de Janeiro, Brasil: Elsevier.

Sampaio, D. A. (2010). Imagem corporal e excesso de peso em adolescentes (Dissertação de mestrado). Faculdade de Ciências da Universidade de Lisboa, Portugal.

Santos, M. J., Silva, I., \& Cardoso, M. H. (2009). Avaliação da qualidade de vida e do controlo glicémico em diabéticos tipo 1 com bomba infusora de insulina. Revista Portuguesa de Endocrinologia Diabetes e Metabolismo, 4(1), 33-42.

Sociedade Portuguesa de Diabetologia. (2015). Diabetes: Factos e números 2014: Relatório anual do observatório nacional da diabetes. Lisboa, Portugal: Autor.

World Heatlh Organization (2011). Adolescent health. Geneva, Switzerland: Author. 